BMJ Paediatrics Open

\title{
Use of melatonin: a single-centre audit
}

\author{
Rebecca Dack 자 , ' Joanna J Garstang
}

2,3

To cite: Dack R, Garstang JJ. Use of melatonin: a single-centre audit. BMJ Paediatrics Open 2022;6:e001349. doi:10.1136/ bmjpo-2021-001349

Received 29 November 2021 Accepted 2 January 2022
Check for updates

\section{(C) Author(s) (or their} employer(s)) 2022. Re-use permitted under CC BY-NC. No commercial re-use. See rights and permissions. Published by BMJ.

${ }^{1}$ Child Health, UHNM, Stoke-onTrent, UK

${ }^{2}$ Children and Family Services, Birmingham Community Healthcare NHS Trust, Aston, UK ${ }^{3}$ Institute of Applied Health Research, University of Birmingham, Birmingham, UK

\section{Correspondence to} Dr Rebecca Dack; rebeccadack@nhs.net

\section{ABSTRACT}

Sleep disorders in childhood are common. Melatonin is prescribed by UK community paediatricians to treat sleep disorders, but practice is not standardised. This audit reviewed melatonin prescribing within a community paediatric department in a 12-month period. 682 children received melatonin prescriptions; a random sample of 198 records were reviewed. The most common underlying condition was autism spectrum disorder (ASD) in $28 \%$. $41 \%$ had no underlying diagnosis when melatonin was initiated and were waiting for neurodevelopmental/ASD assessment. 42\% were on melatonin for at least 2 years. Further work is required to optimise melatonin prescribing practice for children and young people.

Up to $40 \%$ of children experience sleep problems during childhood. This increases to $86 \%$ for children with additional needs, including neurodevelopmental disorders such as autism spectrum disorder (ASD). ${ }^{1}$

Melatonin is frequently prescribed by community paediatricians in the UK to treat sleep disorders in children. There is no national guidance regarding the prescribing of melatonin for sleep difficulties in children, but a research study by Gringras et al demonstrated its effectiveness for children with ASD. ${ }^{2}$

The purpose of this audit was to review current practice relating to the prescribing of melatonin by community paediatricians, within an acute trust in the West Midlands, UK.

Retrospective data were collected. A list of all melatonin prescriptions dispensed for patients aged 0-16 years between 1 August 2017 and 31 July 2018 was obtained from the hospital pharmacy. A random sample was selected; outpatient clinic letters available in electronic medical records of those selected were reviewed. Data were logged on an excel database.

Data variables collected included dose, formulation, duration, diagnosis.

\section{PATIENT AND PUBLIC INVOLVEMENT}

Patients were not involved in this project.

A total of 2423 melatonin prescriptions for 682 children were dispensed during the study period. Of $205(30 \%)$ electronic medical records were randomly selected for review, seven prescribed by general paediatricians were excluded.

Of $81 / 198$ (41\%) children had no diagnosed condition when starting melatonin, many were on waiting lists for ASD assessments, others being monitored by community paediatricians without further neurodevelopmental assessment planned.

The most common diagnosis was ASD in 55 children (28\%) (figure 1). In our trust, children with attention-deficit hyperactivity disorder are managed by mental health services not paediatricians.

There were 22 different dosing regimens and four different preparations prescribed (liquid, capsules, tablets, modified-release tablets). Seventy-seven children (39\%) were on doses of $3 \mathrm{mg}$ or less. There were several cases where doses of $10 \mathrm{mg}$ or more had previously been used and subsequently reduced. Current prescriptions for 194 (98\%) of cases were for doses less than $10 \mathrm{mg}$.

Eighty-six (43\%) children had been on melatonin for at least 2 years (figure 2).

This audit shows that multiple different prescribing practices are used for melatonin by community paediatricians within the same department. Children remain on melatonin for years and the majority of these children require appointments in secondary care medical clinics to review this.

At the time of this audit, there was no licensed paediatric melatonin product. Slenyto has since been licensed for use in children with ASD, but $41 \%$ of prescriptions were for children with no underlying diagnosis or awaiting assessment. It is recognised nationally that waiting lists for ASD assessments are lengthy, but sleep specialists recommend avoiding melatonin for children mid-assessment. ${ }^{3}$ There remains a large cohort of children that have conditions where melatonin is not licensed but recognised to be of clinical benefit. ${ }^{4}$

Advice on sleep hygiene is given at medical appointments, but the department relied heavily on melatonin to manage sleep problems, there was no specialist sleep service and 


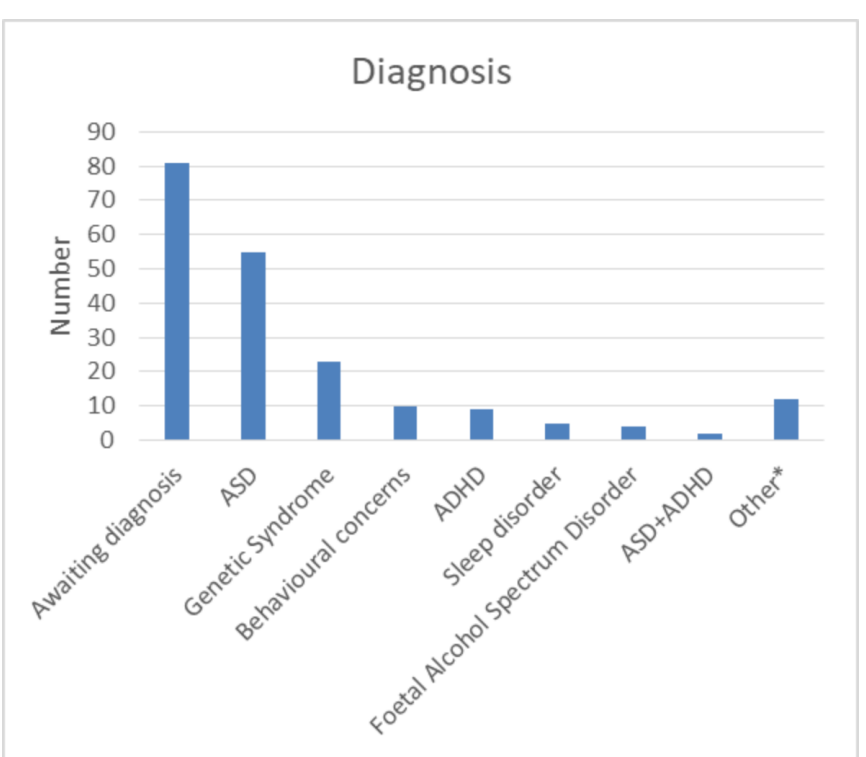

Figure 1 Diagnosis. *Including: epilepsy, learning disability, cerebral palsy, children under oncology care, migraines, breath holding. ADHD, autism spectrum disorder; ASD, autism spectrum disorder.

little behavioural support available to families; reflecting community paediatric practice in much of the UK. There is evidence that good sleep hygiene alone can result in better sleep in childhood, and access to support can reduce reliance on medication. ${ }^{5}$

Community paediatric departments should explore options for increasing behavioural intervention to

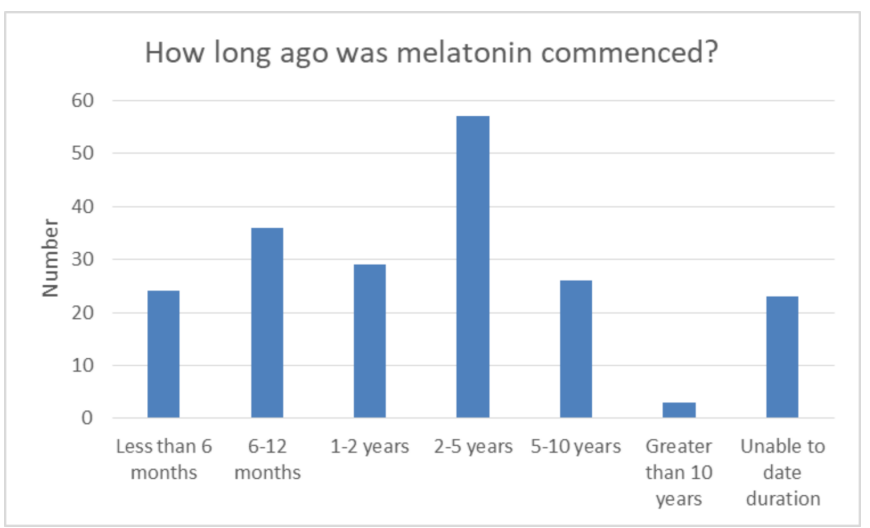

Figure 2 How long ago was melatonin commenced? further reduce the emphasis on medication for sleep difficulties in children. Where medication use is unavoidable, we recommend that further work is undertaken to develop clear guidelines to optimise the management of melatonin prescribing for children.

We suggest that melatonin management could be better achieved in dedicated sleep clinics; potentially nurse-led. Alternatively, primary care could take over the management for children with sleep difficulties who do not require specialist follow-up, but it would be important to ensure they have access to behavioural advice.

Contributors RD designed the project, collected and analysed data. RD and JJG wrote the article.

Funding The authors have not declared a specific grant for this research from any funding agency in the public, commercial or not-for-profit sectors.

Competing interests None declared.

Patient consent for publication Not applicable.

Ethics approval This study does not involve human participants.

Provenance and peer review Not commissioned; externally peer reviewed.

Supplemental material This content has been supplied by the author(s). It has not been vetted by BMJ Publishing Group Limited (BMJ) and may not have been peer-reviewed. Any opinions or recommendations discussed are solely those of the author(s) and are not endorsed by BMJ. BMJ disclaims all liability and responsibility arising from any reliance placed on the content. Where the content includes any translated material, BMJ does not warrant the accuracy and reliability of the translations (including but not limited to local regulations, clinical guidelines, terminology, drug names and drug dosages), and is not responsible for any error and/or omissions arising from translation and adaptation or otherwise.

Open access This is an open access article distributed in accordance with the Creative Commons Attribution Non Commercial (CC BY-NC 4.0) license, which permits others to distribute, remix, adapt, build upon this work non-commercially, and license their derivative works on different terms, provided the original work is properly cited, appropriate credit is given, any changes made indicated, and the use is non-commercial. See: http://creativecommons.org/licenses/by-nc/4.0/.

ORCID iDs

Rebecca Dack http://orcid.org/0000-0001-5250-4639

Joanna J Garstang http://orcid.org/0000-0001-9268-0581

\section{REFERENCES}

1 Dawson V. Sleep. BACCH News:15-17.

2 Gringras P, Nir T, Breddy J, et al. Efficacy and safety of pediatric Prolonged-Release melatonin for insomnia in children with autism spectrum disorder. J Am Acad Child Adolesc Psychiatry 2017:56:948-57.

3 McDonald A, Joseph D. Paediatric neurodisability and sleep disorders: clinical pathways and management strategies. BMJ Paediatr Open 2019;3:bmjpo-2018-000290.

4 Esposito S, Laino D, D'Alonzo R, et al. Pediatric sleep disturbances and treatment with melatonin. J Trans/ Med 2019;17:77.

5 Mindell A, Meltzer L, Carskadon M. Developmental aspects of sleep hygiene. Sleep Med 2009;10:771-9. 